\title{
Salud Bucal en Pediatría
}

\section{Oral Health in Pediatrics}

\author{
Stela Benítez de Forcadell ${ }^{1}$
}

La salud bucal es primordial porque tiene implicancias en la salud general y en el bienestar del individuo. En el caso de los niños, adquiere especial relevancia, por la repercusión que tiene en él como niño, y en el día de mañana como adulto porque puede tener consecuencias en la formación de su personalidad $^{(1,2) \text {. }}$

La cavidad bucal puede presentar signos de enfermedad, hábitos deletéreos, carencias nutricionales, consumo de sustancias nocivas, como cigarrillos, alcohol, estupefacientes e inclusive, denotar algún tipo de violencia física. Las infecciones periodontales son factores de riesgo para la salud y existen evidencias de que predisponen a partos prematuros con nacimiento de niños de bajo peso, que pone en riesgo su vida, bacteriemias, agravamiento de enfermedades sistémicas, como epilepsia, diabetes, entre otros. Estas enfermedades se dan en niños y adultos. Actualmente, se tiene embarazos de niñas a muy temprana edad. Las periodontopatías sumadas a la corta edad de estas madres pueden poner en riesgo su vida y la del bebé ${ }^{(3,4)}$.

La boca cumple varias funciones, una de ellas es iniciar la digestión, si en este sitio el organismo no es capaz de realizar la primera etapa de la digestión, que es la masticación con la creación del bolo alimenticio, todo el aparato digestivo se resiente, sobrecargando al organismo al mismo tiempo porque no se aprovechan todos los nutrientes, debido a que las enzimas propias de la saliva, no pudieron realizar su función en forma óptima, porque los dientes no trituraron correctamente los alimentos; que es una función cumplida por las piezas dentarias posteriores $^{(5)}$.
Es muy agradable sonreír y mostrar unos dientes relucientes, esa es la función social de los dientes anteriores. Un niño con problemas de caries o ausencias de piezas dentarias ${ }^{(4)}$ anteriores por lo general sufre bullying o acoso escolar, tan popular hoy en día en los colegios de todos los estratos sociales. Se debe tener presente que la personalidad del niño se forma a temprana edad y un factor muy importante para la maduración social es la aceptación de los pares. Aquel niño acosado permanecerá apartado del grupo, no podrá compartir los momentos importantes y necesarios para ir desarrollando y poniendo a prueba sus habilidades sociales, tan necesarias para el día de mañana. Si se considera que el ser humano es un ente social y que necesita estar inmerso en una sociedad donde debe participar activamente para poder sobrevivir, con logros y decepciones de toda índole lo anteriormente expuesto tiene que ser tenido en cuenta para aplicar las correcciones en caso necesario. Y especialmente, donde deberá considerar las opiniones de los demás, independientemente que se esté o no de acuerdo, según el rol que le toque desempeñar en la sociedad donde vive ${ }^{(5)}$.

Las piezas dentarias temporarias, individualmente, cumplen funciones muy importantes, una de ellas es mantener el espacio para el sucesor permanente. Si se pierden a muy temprana edad, y no se toman los recaudos necesarios, dichos espacios pueden cerrarse, y la pérdida de espacio, es uno de los factores que originan las malas oclusiones que para la Organización Mundial de la Salud, figura en tercer lugar en la escala de prioridades relacionadas a problemas de salud bucal. Los primeros lugares ocupan las caries y las periodonciopatías ${ }^{(6)}$.

\footnotetext{
${ }^{1}$ Universidad Nacional de Asunción, Facultad de Odontología. Asunción, Paraguay. Correspondencia: Stela Mary Benitez de Forcadell; Correo: stelamary@hotmail.es 
En Paraguay, según la Dirección de Salud Bucodental del Ministerio de Salud y Bienestar Social, $98 \%$ de la población sufre de problemas bucodentales desde muy temprana edad. Esto afecta de diversas formas a la persona, produciendo dolor, baja autoestima, pérdida de capacidad funcional, como alteraciones masticatorias, fonéticas, masticación unilateral, deglución atípica, interposición lingual o labial entre otros. En niños, esta situación puede tener secuelas que disminuyen las oportunidades para un adecuado desarrollo social, que más adelante repercute en el desempeño laboral, económico y la calidad de vida en general. Aunado a estos problemas está el alto costo de los servicios en el sector privado y los tratamientos no cubiertos en el sector público ${ }^{(7,8)}$.

Considerando todas las repercusiones que tiene una salud bucal deficiente y las secuelas que puede dejar en los niños si los afecta desde muy temprana edad, se debe educar a los padres sobre los cuidados orales de manera que conozcan los factores de riesgo de las enfermedades bucales. También se debe tener presente que el gasto de un programa de prevención es siempre menor que aquellos programas destinados a eliminar o paliar la enfermedad una vez ya producida.

\section{REFERENCIAS BIBLIOGRÁFICAS}

1. Cerón-Bastidas XA. Relación De Calidad De Vida Y Salud Oral En La Poblacion Adolescente. CES Odontol [Internet]. 2018; [Consultado el 5 de Diciembre de 2018 ] 31(1):38-46. Recuperado apartir de: http://revistas.ces.edu. co/index.php/odontologia/article/view/4233/pdf

2. Tolentino VER. Salud bucal y calidad de vida en gestantes del Centro de Salud Cooperativa Universal febrero-julio 2016. Horizmed [Internet]. 2017; [Consultado el 5 de Diciembre de 2018] 17(4):35-41. Recuperado apartir de: http://www.scielo.org.pe/pdf/hm/v17n4/a07v17n4.pdf

3. Mora PC, Alvarez MI, Nlanco HA, Morera PA, Macías MA. Hábitos bucales deformantes en niños de 5 a 11 años. Medisan [Internet]. 2014; [Consultado el 6 de Diciembre de 2018] 18(5):606-12. Recuperado a partir de: http://apps.webofknowledge.com/full_record.do?produc $\mathrm{t}=\mathrm{UA} \&$ search_mode=GeneralSearch\&qid=161\&SID $=\mathrm{V} 1 \mathrm{C}$ lbAN8Goxdltu4QJu\&page $=1 \&$ doc $=1$

4. Gonzalez GX, Cardentey J, Porras MO. Manifestaciones clínicas de la enfermedad periodontal en gestantes de un área de salud en Pinar del Río. MEDISAN [Internet]. 2017; [Consultado el 6 de Diciembre de 2018] 21(12):9. Recuperado apartir de: http://scielo.sld.cu/pdf/san/v21n12/san072112.pdf

5. Fort A, Fuks AJ, Napoli AV, Palomba S, Pazos X, Salgado $\mathrm{P}$, et al. Distribución de caries dental y asociación con variables de protección social en niños de 12 años del partido de Avellaneda, provincia de Buenos Aires. Salud Colect [Internet]. 2017; [Consultado el 7 de Diciembre de 2018] 13(1):91-104. Recuperado apartir de: https://www.sc ielosp.org/article/ssm/content/raw/?resource_ssm_path=/ media/assets/scol/v13n1/1851-8265-scol-13-01-00091.pdf

6. Pérez Y, Granados E, Aranda S, Arocha A, Aranda Godínez MS. Maloclusiones y hábitos bucales deformantes en escolares con dentición mixta temprana. Medisan [Internet]. 2016; [Consultado el 7 de Diciembre de 2018] 20(4):426-32. Recuperado apartir de: http://scielo.sld.cu/scielo.php?script=sci_arttext\&pid=S10 29-30192016000400002\&lng=es

7. Díaz-Reissner C, Pérez-Bejarano N, Sanabria D, FerreiraGaona M, Cueto N, Urquhar D, et al. Nivel de conocimiento sobre prevención de caries dental en universitarios. CES Odontol [Internet]. 2016; [Consultado el 8 de Diciembre de 2018] 29(1):14-21. Recuperado apartir de: http://www.scielo.org.co/pdf/ceso/v29n1/v29n1a03.pdf

8. Sanabria-Castellanos CM, Suárez-Robles MA, EstradaMontoya JH. Relación entre determinantes socioeconómicos, cobertura en salud y caries dental en veinte países. Rev Gerenc y Polit Salud [Internet]. 2015;14(28):161-89. Recuperado apartir de: http://www.scielo.org.co/pdf/rgps/v14n28/v14n28a12.pdf 